JEICOM, Vol.2, Issue 2, December 2020. Reevaluating the role of innovation in education: a living social process. Preface. Dr Fotini Diamantidaki \& Dr Margarita Kefalaki

\title{
Reevaluating the role of innovation in education: a living social process Preface
}

Journal of Education, Innovation and Communication (JEICOM)

Vol. 2. Issue 2, December 2020 DOI: $10.34097 /$ jeicom-2-2-Dec2020-0

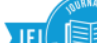

\author{
Dr Fotini Diamantidaki \\ $\&$ \\ Dr Margarita Kefalaki ${ }^{2}$
}

Education is a social process, 'a process of living and not a preparation for future living' (Dewey: 1916). It requires educators to interact with other people in real time with the hope to bring out their full potential. It is grounded in collaboration, mutual respect and inclusive practices. If education is a process of living and not a preparation for it, it should then reflect what happens in life and it should emerge and evolve from any circumstances. Including the most unprecedented ones.

Innovation equally emerges from unpredictable circumstances - 'Necessity is the mother of invention' (Plato in Ferrari: 2000). Educational innovations aim to improve teaching and learning, social innovations aim to improve the way we live. Lately, innovation is particularly associated alongside advances in technology; however, technological innovations need a strong theoretical foundation, a systematic purposeful approach and a grounded theory in pedagogy (Serdyukov, 2017). However, at the core of any advancement is us humans: 'the real mechanism to influence our future is a distinct sphere of human culture' (Mykhailyshyn et al., 2018: 10).

Our issue aims to add to the existing knowledge on innovation that have influenced teaching and learning processes during the pandemic with the hope that this issue will help us reevaluate the purpose of innovations and their impact on our everyday life.

\footnotetext{
${ }^{1}$ Lecturer in Languages Education, UCL centre of Applied Linguistics, UK. Email: f.diamantidaki@ucl.ac.uk

${ }^{2}$ Adjunct Professor, Hellenic Open University \& President, COMinG, Greece. Email: mke@coming.gr
} 
JEICOM, Vol.2, Issue 2, December 2020. Reevaluating the role of innovation in education: a living social process. Preface. Dr Fotini Diamantidaki \& Dr Margarita Kefalaki

Professor Justin Peter O'Brien, signs the first paper of this issue, entitled 'Why do digital teaching innovations so often fail?' This research paper makes a case to dispel the unhelpful narrative of technophobic instructors struggling to teach homogeneous tech savvy digital natives, but to recognise a nuanced continuum of digital capabilities, for both students and instructors. The author suggests that educators should seek to collaborate with students to choose how they interact using digital tools, recognising the importance and diversity of public-private boundaries and consider the need for this to take place beyond the gaze of faculty.

The second paper by Dr Arthur W. Shelley, entitled 'Reverse Bloom: A new hybrid approach to experiential learning', brings forward three key new contributions to the literature; The "Reverse Bloom Learning Framework" (RBLF), a set of principles to guide learning facilitation through the RBLF and insights on designing inclusive learning activities (including provision of deeper feedback for better reflection and higher quality learning outcomes). The article argues that these three elements together of progressive learning can enable a more balanced approach to learning at all levels. The RBLF includes all three of Bloom's domains in iterative social learning experiences and reverses the traditional order of Bloom's learning elements. The author suggests that the inclusive and comprehensive approach enables facilitation of more collaborative learning and this generates more competent, confident and capable graduates, who are better equipped to interact in our modern challenging workplaces and our wider world.

John Kinzer, Dr Nathaniel Herbst, Philip Pohlman and Erin Herbst, sign the third paper entitled 'Equipping Parents for Effective HOME Schooling'. The study presents a brief review of a cross-section of the literature on homeschooling issues as well as a succinct case study of a hybrid homeschool service. Based on that analysis, the authors present four ways to help equip parents for effective homeschooling and summarized into the HOME acronym. The acronym stands for $(\mathrm{H})$ helping families find their fit, $(\mathrm{O})$ offering a diversity of teaching resources, (M) making homeschooling socially acceptable, and (E) empowering homeschool partnerships.

Qing Li and Dr Fotini Diamantidaki sign the last article of this issue with an empirical paper entitled 'Evaluating Mandarin language students' online experience during Covid-19: A case study from London' examining teacher-student interactions that take place via online means and the students' sense of 'presence' (i.e., cognitive, social, and teaching presence) in order to evaluate the lessons we can learn from the online learning experience, going forward in terms of teaching and learning. This study also presents how meaningful and worthwhile 
JEICOM, Vol.2, Issue 2, December 2020. Reevaluating the role of innovation in education: a living social process. Preface. Dr Fotini Diamantidaki \& Dr Margarita Kefalaki

the experience has been and how the sense of 'presence' plays a significant role in the process of online teaching and learning.

Finally, in this issue we present a book review by Dr. Sotirios G. Maipas for a book entitled 'Why is it worth waking up every morning?' The book itself aims to provide encouragement with impressions and reflections on inspiration, motivation, and collaboration and is created as a sign of hope, especially during the difficult times we face as a global collective (ex. COVID-19 global crisis, 2020). The publication is a production of well known educators from all over the world and means to give a good example of collaboration, an example of humanity, dignity, hope and sensibility. The President and the Honorary Vice Presidents of the Communication Institute of Greece, creators of this book are, Dr Margarita Kefalaki, Sophia Karanicolas, Dr Michael A. Altamirano, Dr Ailson J. De Moraes, Dr Fotini Diamantidaki, Dr Robert J. Bonk, Dr Carolin Rekar Munro, Dr Jürgen Rudolph, Dr Christian Schnee, and Dr Karl-Heinz Pogner.

\section{References}

Dewey, J. (1916). Democracy and education: An introduction to the philosophy of education. New York: MacMillan.

Ferrari, G.R.F (2000) (Ed). Plato 'The Republic' (Cambridge Texts in the History of Political Thought), Cambridge University Press.

Mykhailyshyn H. Innovation of Education and Educational Innovations in Conditions of Modern Higher Education Institution / H. Mykhailyshyn, O. Kondur, L. Serman // Journal of Vasyl Stefanyk Precarpathian National University. - 2018. - Vol. 5. - № 1. P. 9-16, doi: 10.15330/jpnu.5.1.9-16, http://lib.pu.if.ua:8080/bitstream/123456789/1431/1/2793-8202-1-PB.pdf

Serdyukov P. (2017) Innovation in education: What works, what doesn't, and what to do about it? Journal of Research in Innovative Teaching \& Learning, 10 (1) (2017), pp. 433. 